\title{
Applied Behavior Analysis: Teaching Procedures and Staff Training for Children with Autism
}

\author{
Carolyn S. Ryan \\ Institute for Children with Autism and Related Disorders and \\ Queens College of the City University of New York, CUNY, \\ United States of America
}

\section{Introduction}

The current chapter will present an overview of current effective teaching methods for children with autism. Applied behavior analysis has been referred to as the treatment of choice for those with autism (United States Surgeon General, 1999; New York State Department of Health, 1999a, 1999b, 1999c). At its core, applied behavior analysis is the data- and research-based application of behavioral principles to socially relevant behavior (Baer, et al., 1968; Cooper, et al., 2007; Wolf, 1978). Additional key components of applied behavior analysis are generalizability, conceptually systematic, technologically sound, practical, and effective (Baer, et al., 1968). These key components will be described below.

Due to the pervasive nature of autism that results in dramatic impairments in communication and social behavior, along with restricted and repetitive behavior - the primary goals of treatment are to improve the child's communication and social behavior as well as reduce the occurrence of restricted and repetitive behavior (American Psychiatric Association, 2000). Applied behavior analysis has been demonstrated to be the treatment of choice for students with autism based on over 40 years of supportive evidence in improving social behavior and communication and reducing levels of problem behavior (Lovaas, 1987). The methods used in applied behavior analysis focus on targeting specific behavior, defining the behavior, designing an intervention to meet the goal of behavior change, implementing the intervention, analyzing the effectiveness of the intervention, and continuing the intervention or designing a procedure to maintain the behavior change (Cooper et al. 2007).

Research approaches for teaching students with autism have been effective across social, communication, and problem behavior areas (Smith, 2001). Teaching methods will be reviewed in the current chapter along with staff training methods for building effectiveness and competency with those who teach students with autism (Reid \& Green, 1980; Ryan \& Hemmes, 2005, Ryan, et al., 2008).

\section{Applied Behavior Analysis - key components}

This section of the chapter presents key terms as a review in applied behavior analysis (ABA). The brief review describes terms that are important for understanding the remainder of the chapter. ABA is a scientific method of teaching that is based on the principles of 
learning and behavior in which each target behavior is operationally defined and modified. Key components of ABA will be described below.

ABA is the systematic, controlled, and empirical investigation of socially important behavior using empirically validated research-based and socially acceptable practices (Baer, et al., 1968; Cooper, et al., 2007, Newman et al., 2003). When we consider how socially important behavior change is, some considerations for a given individual, include: chronological age, behavioral repertoire, community, developmental age, family background, religious values, ethnicity, and other factors important to the individual. In addition, we consider approaches to behavior changes that are socially valid (Wolf, 1978).

A second key component is that ABA is behavioral (Baer, et al, 1968; Newman et al., 2003). Practitioners of ABA studies observable, measurable responses. Data are collected in an ongoing manner. In teaching situations, repeated measurement and graphing of performance in a systematic way assists in monitoring progress over time. This allows continuous assessment of the effectiveness of teaching methods to guide trainers and teachers to modify programs and curricula to increase learning. In addition, monitoring and modifying staff behavior is crucial to a successful program. Furthermore, because objectivity is essential to science, reliability measures of all those involved are systematically obtained through inter-observer agreement data collection.

ABA is analytic, meaning, empirical demonstration of functional relations between antecedent events, behavior, and consequent events (Baer, et al, 1968). All teaching methodology stems from research empirically demonstrating the effectiveness of stimuli presented by teachers before and after student performance. Furthermore, functional analysis of problem behavior is performed before implementation and continuation of behavior reduction programs.

ABA is technological (Baer, et al, 1968). All behavior that needs to be changed is precisely defined, and all procedures and methods used are explicitly described in a step-by-step fashion. ABA is also conceptually systematic, since all of its technology is directly related to the field of the experimental analysis of behavior.

$\mathrm{ABA}$ is committed to teaching skills that are practical, effective, and can generalize to other responses, people, or settings (Baer, et al, 1968). Every educational program is selected according to whether it is appropriate, meaningful, and functional for the individual student. Research in applied behavior analysis strives to answer questions, such as:

- Is the skill likely to be maintained in the everyday, natural environment?

- Are the responses going to help improve the quality of the person's life?

- Can programming be conducted for generalization of skills to be used outside the teaching situation or learning environment?

- Can skills be taught so that generalization is shown spontaneously?

Continuous research is directed toward answering the above questions and to measure and to increase the effectiveness and generality of applied behavior analytic methodology.

In terms of how ABA may benefit students with autism, there are several considerations (New York State Department of Health, 1999a, 1999b, 1999c). Each student is systematically observed for current behavioral functioning. Based on the student's behavior repertoire, behavior excesses and deficits are identified and long-term and short-term goals are devised. Each student is taught using an individualized curriculum using positive reinforcement to encourage accurate responding. Programs and treatment plans are research- and data-based. Programs include an individualized teaching strategy. The effectiveness of teaching and treatment implementation is evaluated in an ongoing manner 
using specific data-collection procedures, including visual displays, such as, graphs or charts. Data collection is used to evaluate the progress of the student and the teaching professionals.

In summary, $A B A$ is critical in the education and intervention for students with autism. Some important factors in the realm of ABA as related to students with autism are as follows. There is a strong emphasis on defining problems in terms of behavior that can be operationally defined and measured. Increases or decreases in the target behavior indicate the extent to which behavior changed or improved. Teaching and treatment procedures are designed to assist each person to function more fully in society. Methods and rationales are described and defined. Socially important changes are demonstrated using scientific demonstrations that are explicated using single-subject research designs. In addition, there is a very high value placed on all those involved in the education of students with autism.

\section{Applied Behavior Analysis - forms of behavior}

Two forms of behavior are respondent and operant behavior (Cooper et al., 2007). Respondent behavior refers to reflexive responses that are elicited by certain stimuli and over which individuals have little or no control (e.g., sneezing, blinking, or emotional responses). New reflexive behavior can be learned by pairing the stimulus or unconditioned stimulus (US) that controls the reflexive response or unconditioned response (UR) with a new stimulus that is initially the neutral stimulus (NS). Based on pairing the NS with the US, the NS then becomes the conditioned stimulus (CS) that will elicit the conditioned response (CR). The CR will be similar, in most cases, to the UR; however, there may be differences in the magnitude, latency, topography, and/or other response measures. Associations between stimuli can be learned; reflexive behavior can occur in response to new stimulus associations. Reinforcer inventories and assessments involve respondent behavior, in that, individuals act pleasantly, unpleasantly, or neutral when presented something preferred, nonpreferred, or neutral, respectively. Emotions are often described in terms of respondent behavior. Unconditioned and conditioned emotional responses are terms used in the same manner as described above.

Operant behavior refers to behavior that is emitted as a result of its history of consequences. Operant behavior is different from respondent behavior because operant behavior is selectively targeted and maintained by the consequences that it has produced. New operant behavior can be learned and maintained using consequences. Providing a preferred activity immediately after a response occurring will most likely increase the response occurrence in the future. For example, if a student says, "Can I listen to music?" and earns listening privileges, most likely the requesting behavior will occur again in the future. On the other hand, providing a non-preferred activity to a student immediately after a response occurring will most likely not increase the response occurrence in the future; in fact, the response may not occur again in the future. For example, if a student attempts to gain someone's attention by throwing puzzle pieces on the floor that is then followed by the teacher's request to have the student clean up (if she does not enjoy cleaning up), most likely the throwing behavior will not occur again in the future.

These features imply that students may be taught appropriate, functional responses that may be new responses or replacements for problem responses. In addition, the deficits or lack of appropriate skills shown by students with autism may be related to physiological, covert events, as well as a lack of appropriate educational practice. 
Operant behavior is modified by antecedent and consequent events. Antecedent events are those that precede responses. Discriminative stimuli are events that set the occasion for a response to occur. Consequent events are those that follow behavior; these may be reinforcing, punishing, or neutral. Preferred events that follow a response can be viewed as reinforcers if they increase the probability of the future occurrence of the response. Nonpreferred events that follow a response can be viewed as punishers if they decrease the probability of the future occurrence of the response. Neutral events that follow a response do not affect the probability of the future occurrence of the response. In effective educational procedures, consequences are contingent on behavior; the responses should produce the consequences contingently. As a result of the modification of antecedent and consequent events in order to influence the occurrence of responding, the diagnostic label for an individual is not useful.

Direct behavioral observation can allow one to describe the target behavior or response by specifying, in written form:

- what the behavior is,

- how much, how well, or how often the behavior is done, and

- the circumstances (when and where) under which the behavior is done.

After the target behavior or response is described, measurement of the target behavior on an ongoing basis can be conducted. Decisions about educational procedures are made according to the data collected. Continuation, modification, or discontinuation of educational procedures is conducted according to behavioral progress.

\section{Applied Behavior Analysis - five step model}

The following five step model may be used as a guide in understanding ABA (Cooper et al., 2007):

1. Select behavior to be analyzed:

- Assess behavior of interest

- Operationally define the target behavior

- Establish priorities, goals, and objectives

- Analyze the system, obtain involvement and support from intervening agents

2. Measure the behavior:

- $\quad$ Select measurement procedures

- Collect data, including baseline data

- Continue data collection on an ongoing basis

3. Select treatment procedures:

- Identify current contingencies

- $\quad$ Select materials, equipment, and setting

- Negotiate treatment plans as needed

4. Implement procedures:

- Monitor effects based on data collection

- Modify procedures as needed

5. Evaluate effects of treatment:

- Data collect

- Modify or fade treatment 


\section{Applied Behavior Analysis - reinforcement and punishment}

Figure 1 displays antecedent and consequent events as related to reinforcement and punishment procedures. Positive reinforcement is a procedure by which a stimulus or positive reinforcer is delivered, given, shown, or otherwise presented, immediately following a target response that serves to increase the future occurrence of that response. There is a positive contingency between a target response and an appetitive stimulus (See Figure 1).

Negative Reinforcement is a procedure by which a stimulus is removed, taken away, turned off, or otherwise withdrawn immediately following a target response that serves to increase the future occurrence of that response. There is a negative contingency between a response and an aversive stimulus (See Figure 1).

There are two types of negative reinforcement trials: escape and avoidance. In escape trials the target response terminates the aversive stimulus, e.g., a student may request a break during a difficult reading task to delay the aversive stimulus of the task. A short-term escape consequence may be taking a 5-min coffee break, whereas, a long-term escape consequence may be leaving an aversive job position and never returning. In avoidance trials the target response prevents the delivery of the aversive stimulus, e.g., before beginning a teaching program, a student may request to use the bathroom and avoid the aversive stimulus of the teaching program. For example, a short-term avoidance consequence may be calling in sick to work, whereas, a long-term avoidance consequence may be never returning to work.

Important Factors for Reinforcement:

- Age-appropriate events

- Choice of reinforcers

- Duration of reinforcing event

- Functionality

- Immediacy

- Motivating operations (establishing and abolishing operations, e.g., deprivation/satiation)

- $\quad$ Varied events

There are several types of reinforcers (Cooper et al., 2007; Newman, et al., 2003). These terms and descriptions follow below.

a. Primary reinforcers are items that are naturally reinforcing, e.g., edible reinforcers, such as food or drink; temperature.

b. Secondary or conditioned reinforcers are items that acquire reinforcing properties through learning and pairing the new items with an already established reinforcer, e.g., activities, candy, games, snacks, toys, or time with a favorite person; sensory reinforcers, such as, auditory, olfactory, tactile, visual, or vibratory.

c. Generalized reinforcers are items that acquire reinforcing properties through consecutive pairing with established reinforcers and can be generally effective in producing behavior change, e.g., grades, money, praise, or stars; social reinforcers, such as, smiling, praise, attention, or otherwise friendly remarks.

d. Positive reinforcers refer to the stimuli involved in positive reinforcement procedures in which an item or stimulus is presented immediately following the target response in order to increase the future probability of that target response e.g., adult attention, hug, or smiles. 
e. Negative Reinforcers refer to the stimuli involved in negative reinforcement procedures in which an item or stimulus that is aversive or unpleasant is removed from the situation immediately following the target response in order to increase the future probability of that target response, e.g., complete a task, finish a difficult chore, or turn off loud music.

There are two motivating operations (MOs) that can be used to describe a level of effectiveness of a reinforcer, i.e., establishing operation (EO) or deprivation and abolishing operation (AO) or satiation (Cooper et al., 2007). Deprivation refers to the establishing operation for which reinforcers have been withheld to the point that the specific reinforcer is effective in increasing or maintaining behavior. Satiation refers to the establishing operation for which reinforcers have been presented to the point that the specific reinforcer is no longer effective in increasing or maintaining behavior.

There are a variety of methods of obtaining reinforcers for a student. Reinforcers are individually-based, meaning that a reinforcer may be a preferred item that a particular student likes or will work towards obtaining.

\section{Diagram of consequences}

The following diagrams are presented to further the understanding of the use of reinforcement. In the case of reinforcement, this procedure involves the presentation (positive reinforcer) or removal (negative reinforcer) of a stimulus immediately following the target response in order to increase the future likelihood of the target response occurring.

STIMULUS

\begin{tabular}{|c|c|c|c|}
\hline & \\
\hline & & PRESENTED & WITHDRAWN \\
\hline PROBABILITY & INCREASE & $\begin{array}{c}\text { POSITIVE } \\
\text { REINFORCEMENT }\left(\mathrm{S}^{\mathrm{R}+}\right)\end{array}$ & $\begin{array}{c}\text { NEGATIVE } \\
\text { REINFORCEMENT (SR-) }\end{array}$ \\
\hline OF BEHAVIOR & DECREASE & $\begin{array}{c}\text { POSITIVE } \\
\text { PUNISHMENT }\left(\mathrm{S}^{\mathrm{P}+}\right)\end{array}$ & $\begin{array}{c}\text { NEGATIVE } \\
\text { PUNISHMENT (SP-) }\end{array}$ \\
\hline
\end{tabular}

The diagram above Fig. 1. shows the relation between types of stimuli and the two reinforcement procedures. In positive reinforcement, an appetitive stimulus or event is presented (positive reinforcer) immediately following the target response to increase the future likelihood of the target response occurring. In negative reinforcement, an aversive stimulus or event is removed immediately following the target response to increase the future likelihood of the target response occurring.

Reinforcers for some students may be playing with bubbles, dolls, games, and toys; hearing praise, seeing someone smile, obtaining tickles, and eating crackers; some other students may prefer playing with racecars, making objects from clay, playing a chase game, obtaining high-fives, and eating apples.

The following methods may be used for obtaining reinforcers:

a. Identify Reinforcers: reinforcers can be assessed based on the general effects that particular items have on the behavior of people similar to the target person, e.g., attention, money, praise, privileges, snacks, toys. Age-appropriateness of the reinforcers should be determined. Preferred items may be obtained by: 


\begin{tabular}{|c|c|c|c|}
\hline & \multicolumn{2}{|c|}{ Reinforcement } & \\
\hline \multirow{2}{*}{ Positive, +} & $\begin{array}{c}\text { Appetitive } \\
\text { Stimulus ( } \uparrow \text { ) }\end{array}$ & $\begin{array}{c}\text { Aversive } \\
\text { Stimulus }(\downarrow)\end{array}$ & \multirow{2}{*}{ Negative, } \\
\hline & $\begin{array}{c}\text { Aversive } \\
\text { Stimulus }(\uparrow)\end{array}$ & $\begin{array}{c}\text { Appetitive } \\
\text { Stimulus }(\downarrow)\end{array}$ & \\
\hline & & & \\
\hline
\end{tabular}

Fig. 2. Diagram of consequences in applied behavior analysis. The upper diagram displays the manner in which a stimulus may be presented or withdrawn immediately following a given target behavior in order to affect the future probability of behavior. The lower diagram displays the qualitative description (appetitive or aversive) of stimulus that may be presented $(\uparrow)$ or removed $(\downarrow)$ immediately following a target behavior along with its associated procedure, namely reinforcement or punishment.

- Asking the person.

- Observing the person.

- Observe similar people.

- Use the Premack Principle*

- Use reinforcer sampling

b. *Premack Principle: A response frequently performed by a student can be used to reinforce a response that the student performs infrequently. A more likely or preferred activity can serve to reinforce a less likely activity, e.g., riding a bike can reinforce homework completion.

c. Reinforcer or Preference Assessment: Indirect and direct methods of assessing preferences are conducted in order establish items that are most favorable for the student. Ultimately, reinforcers may be assessed within a teaching situation based on the student's later frequency of showing the target behavior. If the target response is shown, then the action, item, or other stimulus presented immediately following the target response served as a reinforcer for that target response.

Some Important Factors in the Effective Use of Reinforcers:

- Anticipate generalization by (a) shift from frequent to occasional reinforcement and (b) shift from artificial to natural reinforcement.

- Avoid satiation through (a) the use of a variety of reinforcers and (b) use small amounts.

- Do not allow the reinforcer apart from the teaching situation, or when the target response occurs.

- Establish conditioned reinforcers.

- Make reinforcers contingent on the performance of the target response.

- Present the reinforcer immediately following the target response.

- Reinforcers should be easily administered and rapidly consumed.

- Use conditioned reinforcers to bridge the gap between other reinforcers delivered or the next trial.

- Vary the pace of reinforcement: allow a short interval (2- to 3-second intervals) for reinforcement and change it next time to a longer interval (6- to 10-second intervals).

- Vary the tone of voice used: for the most part, use an enthusiastic voice for reinforcers; however, other tones, may include whisper, deep tones, and loud voice. 
- Vary words and gestures: use different words and expressions, as well as actions and activities to make the session fun and exciting.

Punishment is another behavior analytic procedure that affects the future probability of behavior (see Figure 1). Positive Punishment or Type 1 Punishment is a procedure by which a stimulus or positive punisher is delivered, given, shown, or otherwise presented, immediately following a target response that serves to decrease the future occurrence of that response (Cooper et al, 2007). A stimulus is delivered, given, shown, or otherwise presented immediately following a target response that serves to decrease the future occurrence of that response. There is a positive contingency between a target response and an aversive stimulus.

For example, saying, "No," to a student after he throws a toy on the floor can be assessed as a punisher by measuring the effects on behavior. If "No" decreases the probability of throwing the toy on the floor in the future, then it serves as a positive punisher.

Negative punishment or Type II Punishment is a procedure by which a stimulus is removed, taken away, turned off, or otherwise withdrawn immediately following a target response that serves to decrease the future occurrence of that response (Cooper, 2007). A stimulus is removed, taken away, turned off, or otherwise withdrawn immediately following a target response that serves to decrease the future occurrence of that response.

For example, taking away a preferred toy contingent upon a student screaming can be assessed as a punisher by measuring the effects on behavior. If the toy taken away decreases the probability of screaming in the future, then it serves as a negative punisher.

For purposes of this chapter, reinforcement is explained in detail because the teaching procedures described below relay on reinforcement procedures and simple correction procedure. The description of punishment procedure is limited.

\section{Applied Behavior Analytic teaching procedures}

Teaching procedures based on applied behavior analysis are most effective for students with autism and other related disorders (Cooper et al., 2007; Lovaas, 1987; Sundberg \& Partington, 1998). The purpose of ABA teaching procedures is to understand, improve, and solve behavior issues. Teaching methods are based on research findings. As a science, applied behavior analysis is constantly changing its teaching methods according to scientific evidence. Effective methods of teaching have incorporated the principles of applied behavior analysis. Two methods include discrete-trial teaching and incidental teaching. Both teaching methods are conducted by systematically breaking down the target behavior into smaller components and addressing each response. Each one of these teaching approaches is data-based and research-based procedures. Research has documented that each one of these procedures are effective for teaching specific behavior goals.

\subsection{Discrete-trial teaching}

One effective instructional method for teaching students with autism is discrete-trial teaching (Sarakoff \& Sturmey, 2004; Smith, 2001; Sundberg \& Partington, 1998; Touchette \& Howard, 1984). In discrete-trial teaching, programming is arranged by dividing a large behavior goal into small, component target responses. Those small, component target responses are then taught in a clear, distinct manner. The manner by which the small component responses are taught takes advantage of the three-term contingency in ABA. The three-term or $\mathrm{ABC}$ contingency properly distinguishes among key elements of teaching (see 
Figure 3). The three-term contingency represents the interdependency of three components (Cooper et al., 2007).

SD

(Discriminative Stimulus)

A

(Antecedent Stimulus)

Three-Term or ABC Contingency

$\rightarrow$

$\rightarrow$

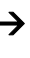

$\mathbf{R}$

(Response)

B

(Behavior)

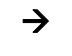

$\mathrm{S}^{\mathrm{r}+/}$

(Reinforcer)

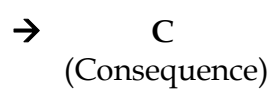

Fig. 3. Three-term contingency

The upper portion of Figure 3, depict the terms in the ABC contingency. The terms used in the $\mathrm{ABC}$ contingency are as follows: antecedent stimulus (A), followed by a given behavior (B), immediately followed by a consequence (C). The ABC contingency is generally interchangeable with the three-term contingency. The terms used in the bottom portion of Figure 3 represent the three-term contingency. The three-term contingency is comprised of the presentation of a discriminative stimulus $(\mathrm{SD})$, followed by a given target response (R), immediately followed by a positive or negative reinforcer ( $\left.\mathrm{S}^{\mathrm{r}+} /-\right)$. For purposes of the current chapter, the three-term contingency will be used to describe the components of discrete-trial teaching.

Discrete trial teaching is the teaching methodology that incorporates the principles of ABA by breaking down tasks into smaller parts and presenting them in a simplified, repeated manner to best facilitate learning (Newman, et al., 2003; Sarokoff \& Sturmey, 2004; Sundberg $\&$ Partington, 1998). Data are collected on each trial to measure and evaluate progress over several trials and teaching sessions. A discrete trial consists of the events depicted in Figure 3 , before making use of the Three Term or ABC Contingency.

Important factors for discrete-trial teaching are considered in its accurate implementation. Discrete-trial teaching makes assessment of progress efficient. In addition, the teaching conditions and requirements are consistent across trials and teaching sessions. There are clear expectations about the requirements of the student. Additionally, discrete-trial teaching makes data collection and observation of the student and the teacher's responses clear and easy to measure.

Discrete-trial teaching is therefore used to: (a) allow data collection and assessment of student and instructor behavior, (b) clarify what is expected of the student and instructor, and (c) maintain consistent teaching conditions and requirements. Green (1996) and Smith (2001) noted that discrete-trial teaching is an effective strategy for teaching new skills with students with autism.

The following describe the required discrete-trial teaching target responses from Ryan \& Hemmes (2005).

"Distraction-free: make the teaching area distraction-free by removing extraneous stimuli, such as sounds, toys, people; reinforcers are within the reach of the instructor and out of the reach or direct view of the child.

Materials: have teaching materials used for the program within reach of the instructor and as needed, the child; containers or boxes should be open or ready for use; items such as edible or tangible reinforcers are within reach of the instructor.

Attending: establish appropriate attending responses by having the child sit or stand with hands and feet still in a position facing the instructor or task materials while 
making eye contact with the instructor or looking at the task materials in anticipation of the delivery of a direction.

Verbal Direction: present a clear, brief, and appropriate instruction appropriate to the program; one particular direction should be presented, with or without a prompt, that was brief in word length; the words should be clearly spoken, concisely presented, and not repeated.

Voice tones: differential voice tones used, i.e., a neutral, directive tone of voice for instructions; an enthusiastic tone of voice for reinforcer words and sounds; a firm voice for corrective feedback.

Wait: allow appropriate amount of time for the child to respond to instruction, approximately $5 \mathrm{~s}$, after an instruction was presented by the instructor, as appropriate to the program.

Praise statement: immediately following a correct response, the instructor will deliver a behavior-specific praise statement specific to the correct target response made by the child, within 2 s - 4 s, e.g., "Great (specified behavior)."

Contingent reinforcers: present primary or secondary reinforcer(s), e.g., tangible, social, or edible, for a brief duration during praise statement, contingent on correct responses.

Prompting and correction procedure: provide an appropriate prompting procedure within $5 \mathrm{~s}$ after the child's failure to respond or an appropriate correction procedure as a predetermined gestural, verbal, and/or physical prompt, immediately following an incorrect response, as appropriate to the program and target response.

Pause for inter-trial interval: allow a brief pause in instruction, up to $5 \mathrm{~s}$, following delivery of the consequential stimuli after a target response and during the inter-trial interval, prior to presenting the next trial.

Incidental or additional teaching: present additional or incidental teaching responses, during the interval following the consequential stimuli presentation, the instructor may make a response related to the reinforcing stimulus or event.

Data recorded: record data for correct or incorrect responses following each of the child's responses, after each trial on the data sheet. " (Ryan \& Hemmes, 2005)

It is critical that the above discrete-trial teaching responses be conducted in the manner described so that teaching is effective and efficient. Staff training on required discrete-trial teaching responses will be described below.

\subsection{Incidental teaching}

Incidental teaching is an applied behavior analytic teaching technique that is used to increase the spontaneous use of language. Incidental teaching occurs within the context of the interactions between two people. An incidental teaching episode begins with an initiation by the first person (the student) who specifies an individual reinforcer; the second person presents a prompt for a language response from the first person and differentially reinforces that language response by the delivery of the reinforcer previously specified by the first person (Hart \& Risley, 1974, 1975, 1980, 2000). Incidental teaching is also one component of naturalistic language training (Hart \& Risley, 1980). Incidental teaching has been used in a variety of ways to promote generalization of language skills (Hart \& Risley, 1974, 1975, 1980, 2000; McGee, et al., 1992). Incidental teaching can be used in a variety of situations and contexts. The important feature is that incidental teaching assists in maintaining language responses. It has been effective for individuals in teaching and maintaining language of students with autism. 
The following required incidental teaching target responses are as follows. A student initiation is

"defined as an unprompted nonverbal or verbal response that indicated a preferred item or activity. Correct performance of incidental teaching, given a student initiation, is demonstrated by five target responses:
(a) watch,
(b) remove,
(c) ask,
(d) pause, and
(e) reward.

Incidental teaching is required to begin within $5 \mathrm{~s}$ of a student initiation. Watch for an initiation was defined as: the instructor is sitting or standing within 1- to 1.5-m of the learner. Remove the desired item was defined as the instructor's making eye contact with the learner for at least $1 \mathrm{~s}$ after a learner initiation, and keeping the requested item or activity away from the learner. Ask for a correct response was defined as the instructor's using an expectant look and one statement or one question to ask the learner to say more about the initiation made. Wait for a correct response was defined as the instructor's allowing up to $10 \mathrm{~s}$ for the learner to respond independently, or providing a prompt after $10 \mathrm{~s}$. Reward was defined as the instructor's presenting behavior-specific praise about the learner's initiation, using an enthusiastic tone of voice, along with access to the object or activity that the learner requested" (Ryan, et al., 2008).

\section{Staff training procedures}

In addition to the research documenting the effectiveness of discrete-trial teaching and incidental teaching procedures, research has supported the effectiveness of staff training procedures to teach the methodology of each of these procedures (Ryan \& Hemmes, 2005; Ryan et al., 2008).

Staff training procedures that are well-established and accepted in the research literature, include: verbal, written, and video instructions; modeling; role-playing; in-vivo practice; and performance feedback (Cullen, 1988; Delamater, et al., 1984; Demchak et al., 1992; Fielding, et al., 1971; Fleming, et al., 1996; Gardner, 1972; Gladstone \& Spencer, 1979; Greene, et al., 1978; Harchik, et al., 1989; Harris, et al., 1975; Johnson \& Fawcett, 1994; Krumhus \& Malott, 1980; Matson, 1990; Neef, et al., 1986; Page, et al., 1982; Parsons \& Reid, 1995; Parsons, et al., 1996; Parsons, et al., 1987; Reid \& Green, 1990; Richman, et al., 1988; Sepler \& Meyers, 1978; Touchette \& Howard, 1984). These established training methods can be used alone or in conjunction with more than one method to promote skill development. In addition, behavior skills training takes advantage of several aspects of the methods mentioned above to train in a concise manner (Sarakoff \& Sturmey, 2004).

\subsection{Staff training on discrete-trial teaching}

Ryan \& Hemmes (2005) examined instructor performance of discrete-trial teaching responses after a performance-based training procedure with a stringent criterion in which instructor were required to show criterion-level performance on written and oral quizzes and on performance demonstrations. Training topics used in the Ryan \& Hemmes procedure are noted below. 


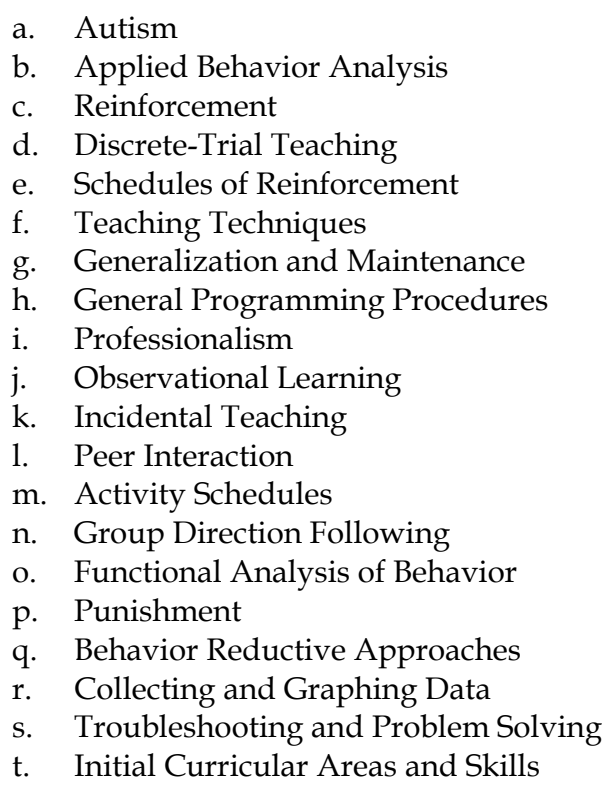

The following training procedures were used: (a) verbal instructions in a lecture format, (b) videotaped instruction, (c) role-playing, and (d) in-vivo training (Arco, 1991; Demchak, et al., 1992; Gardner, 1972; Harris, et al., 1975; Johnson, \& Fawcett, 1994; Matson, 1990; Quilitch, 1975; Sepler, \& Myers, 1978). Discrete-trial teaching responses were labeled and operationally defined as noted above: (a) distraction-free, (b) materials, (c) attending, (d) verbal direction, (e) voice tones, (f) wait, (g) praise statement, (h) contingent reinforcer(s), (i) prompting and correction procedure, (j) pause for inter-trial interval, (k) incidental or additional teaching responses, and (l) data recorded. Systematic measurement of the discrete-trial target responses were obtained during home-based early intervention teaching sessions with young students with autism. The author provided specific performance feedback to instructors after each session.

Instructors were trained on the above training topics. In addition, instructors were specifically trained to emit discrete-trial teaching responses. Following training, accuracy of discrete-trial teaching behavior was assessed during home-based teaching sessions for young students with autism. Feedback for teaching performance was presented following each teaching session during the Post-training phase.

The author scored videotapes of all sessions conducted by each instructor using the datasheet shown in Figure 4. The author then provided feedback to the instructor on accuracy in emitting the 12 responses required for discrete-trial teaching. Video was used in order to decrease the likelihood of reactivity (Hay, et al., 1977). Each session was defined as the presentation of one educational program using 10 discrete trials. One of three categories of educational programs was used: (a) receptive language, (b) expressive language, and (c) nonverbal imitation. Educational programs were devised in accord with each child's educational needs and behavioral repertoire. Educational programs targeted a specific behavior goal. The instructions, prompting procedures, and consequences for an educational program were identical across goals. The consequences for correct responses were behavior-specific praise and an additional reinforcer. 
For a receptive language program, the target response was a nonverbal response specified in the instruction. The instruction for receptive language was, "Point to (item)," with the target item(s) located near the student. The prompting procedure delivered when the student did not respond, was brief physical guidance to have the student use a pointing finger to point. The error correction procedure for an incorrect response was, "This is 'point to (item)'," along with modeling and physical guidance of the response.

For the expressive language program, the target response was a verbal utterance specified in the instruction. The procedure for the expressive language program included a question, e.g., "What do you want?" The appropriate response was "(item)." The prompting procedure was the initial sound of the target response, such as, "ja" for "juice," for the student to repeat the utterance required. The error correction procedure was, "Try again, '(item)'," emphasizing the sound(s) of the word(s) for the student to repeat.

For the nonverbal imitation program, the target response was a nonverbal response that matched the action shown by the instructor. The procedure for the nonverbal imitation program included, "Do this," while modeling the action. The prompting procedure involved physical guidance of the appropriate body part(s) to move as modeled. The error correction procedure was, "This is 'do this'," with physical guidance to have the student perform the target response.

All of the target discrete-trial teaching responses were scored on each trial. Feedback was presented by the author following each videotaped session observation. Praise was provided for accurate target responses. Inaccurate responses were described along with a rationale for change. In addition, a description of correct responding was presented. Acknowledgment from the staff member was requested along with practice of the correct responses. Additional practice using role-play or in-vivo techniques were used in order to demonstrate accurate responses. The author requested instructors to ask questions for clarification. The feedback ended with an appreciation statement.

The results of the discrete-trial teaching staff training procedure showed that each instructor performed at criterion level for all of the quizzes and performance demonstrations. Figure 5 displays the percentage of accuracy for each of the discrete-trial teaching responses recorded for the three Instructors involved in training. Across all three instructors, the mean percentage of accurate responding pooled across 10 sessions was above $89 \%$. Without this level of training, instructors observed as a normative sample showed as low as $48 \%$ accuracy.

Ryan \& Hemmes (2005) assessed the effects of an intensive training package designed to produce high levels of accurate discrete-trial teaching responses through the use of performance criteria. The instructors who participated in the study performed at high mean levels. The importance of requiring performance criteria was explicated from the normative data collected from four instructors of students with autism in a special education setting. Data from the normative sample were considerably lower than those of the instructors from the Ryan \& Hemmes study.

The Ryan \& Hemmes findings concur with those of the literature on the effectiveness of training procedures using verbal and video instruction, modeling, role-playing, in-vivo practice and instruction, and performance feedback in producing accurate teaching performance (Arco, 1991; Cullen, 1988; Fleming, et al., 1996; Harchik, et al., 1989; Krumhus \& Malott, 1980; Parsons, et al., 1996). Reid \& Green, 1980; Sepler, \& Myers, 1978). The Ryan \& Hemmes results are consistent with the findings that individual feedback with praise is crucial in the maintenance of teaching responses (Adkins, 1996; Harchik, et al., Reid \& Parsons, 1995). 
Observer \#/Name:

Discrete-Trial Teaching Data Sheet

Teacher name: Session\#:

Session start time and end time (duration):

\section{Educational Program:}

1. Teaching area distraction-free?

2. Teaching materials available?

3. Attending responses established?

4. One verbal direction only?

5. Voice tones differential, appropriate, and contingent?

6. Wait

D?

7. Praise statement after correct response?

8. Contingent reinforcers?

9. Correction procedure?

10. Pause prior to the next trial?

11. Incidental or additional teaching during pause?

12. Data recorded?

Trial Number

\begin{tabular}{|l|l|l|l|l|l|l|l|l|l|l|l|}
\hline Responses & $\mathbf{1}$ & $\mathbf{2}$ & $\mathbf{3}$ & $\mathbf{4}$ & $\mathbf{5}$ & $\mathbf{6}$ & $\mathbf{7}$ & $\mathbf{8}$ & $\mathbf{9}$ & $\mathbf{1 0}$ & \\
\hline Distraction Free & & & & & & & & & & & \\
\hline Materials & & & & & & & & & & & \\
\hline Attending & & & & & & & & & & & \\
\hline Verbal Direction & & & & & & & & & & & \\
\hline Voice Tones & & & & & & & & & & & \\
\hline Wait & & & & & & & & & & & \\
\hline Praise Statement & & & & & & & & & & & \\
\hline Reinforcers & & & & & & & & & & & \\
\hline $\begin{array}{l}\text { Correction/ } \\
\text { Procedure }\end{array}$ & & & & & & & & & & & \\
\hline Pause & & & & & & & & & & & \\
\hline $\begin{array}{l}\text { Incidental/ } \\
\text { Additional }\end{array}$ & & & & & & & & & & & \\
\hline Record Data & & & & & & & & & & & \\
\hline Mean \% & & & & & & & & & & \\
\hline
\end{tabular}

Fig. 4. Discrete-trial teaching datasheet use din conducting the Ryan \& Hemmes (2005) study. 


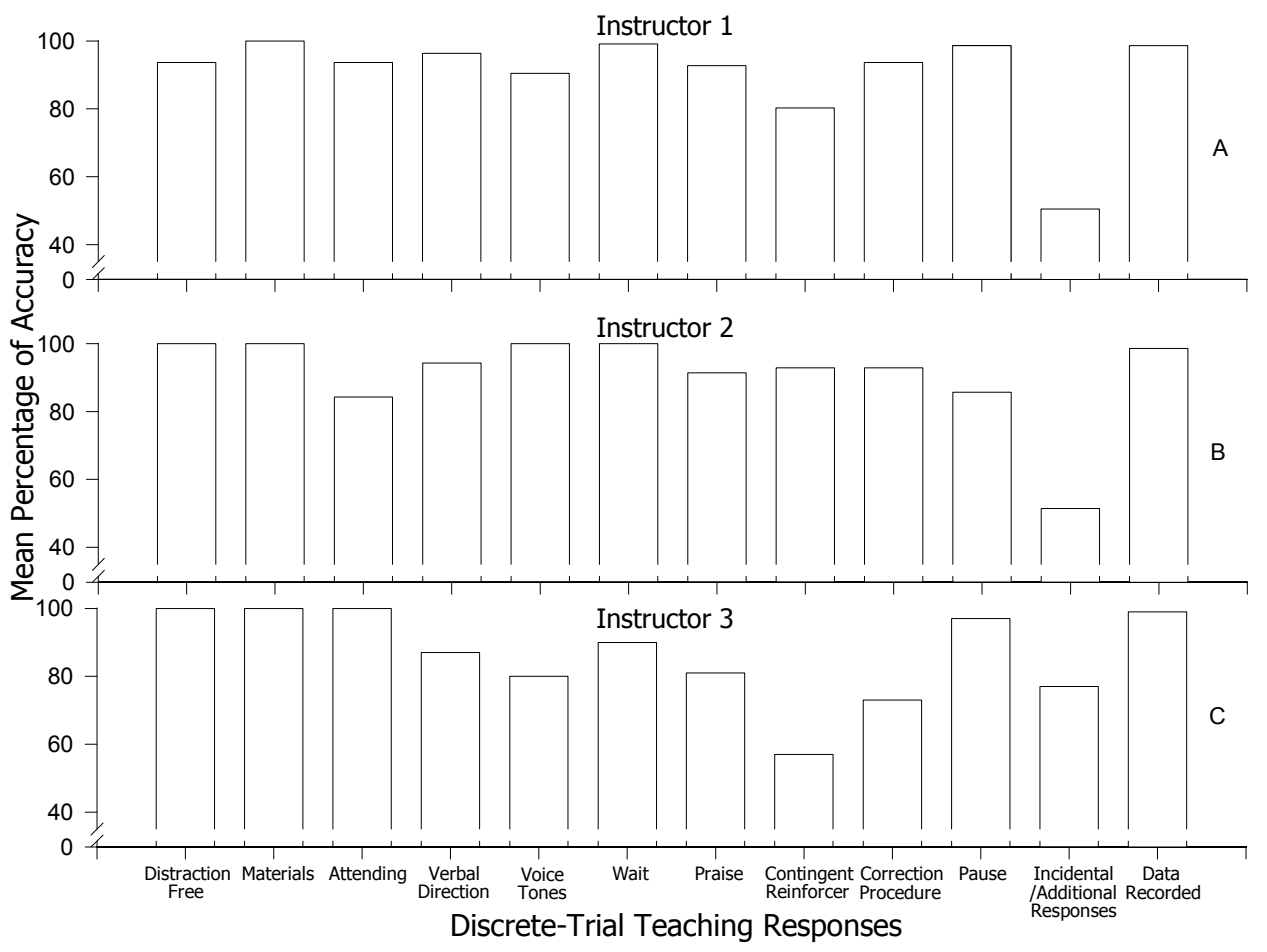

Fig. 5. Figure reprinted with permission from Ryan \& Hemmes (2005). Percentage of accurate responding across the 12 discrete-trial responses for Instructors 1, 2, and 3 as displayed in Panels A, B, and C, respectively.

Mean accuracy of performance for the staff was $92 \%$ or above across 10 sessions. These data were contrasted with the substantially lower levels of accuracy from normative data of instructors conducting sessions in a comparable setting. These data suggest the importance of requiring criterion-level performance during training.

Instructors in Ryan \& Hemmes study showed low accuracy levels of incidental or additional teaching responses. Incidental teaching has been found to be important for arranging opportunities for spontaneous variety and generality in speech in a various settings (Hart \& Risley, 1974, 1975, 1980, 2000; McGee, et al., 1983; McGee, et al., 1985). Instructors were trained to show incidental or additional teaching responses; however, further instruction, as noted below in the following section, may be required to improve performance.

\subsection{Staff training on incidental teaching}

The Ryan \& Hemmes (2005) study highlighted the need for staff training on incidental teaching responses. Due to the nature of incidental teaching, the requirements for stimulus and response generalization in implementing incidental teaching accurately are high (Hart \& Risley, 1974, 1975, 1980, 1982, 1985). At the time of the Ryan et al. (2008) study, there was no research on training staff to implement incidental teaching. Ryan et al. (2008) assessed the effects of a brief group staff training procedure on instructors' use of incidental teaching 
responses and on student initiations. In Experiment 1, instructors of students with autism were provided with an instruction session during which a training package on incidental teaching was presented. The training package included a videotape example of incidental teaching, written text including the definitions and descriptions of incidental teaching, and written incidental teaching scenarios. Posters and wallet-sized cards indicating the required incidental teaching responses were displayed and provided to the instructors (see Figure 6). The data sheet presented in Figure 7 was used during training.

During each session, incidental teaching performance was scored upon the occurrence of each student initiation (see Figure 8 for datasheet). Ryan et al. (2008) labeled and described the terms and definitions of incidental teaching responses as mentioned in the above section. After an initial assessment phase and training session, the author requested that the instructors, "Do this in your classroom." Prior to each session, the author requested that the assistant instructors, "Do your best to get as much language from the students as possible." Instructors from Ryan et al.'s (2008) Experiment 1 showed an increase in the proportion of incidental teaching responses. In addition, improvement in incidental teaching was accompanied by an increase in student initiations. Their data provide evidence for an effective and efficient training method for instructors in setting the occasion for incidental teaching episodes.

A large-scale systematic replication of Experiment 1 was conducted in Experiment 2 in order to evaluate the generality of the findings observed. In addition to the training components of Experiment 1, Experiment 2 included role-playing with feedback during training. Pretraining sessions were conducted prior to training; post-training sessions were conducted within one week after Training. After training, the author asked each participant to demonstrate incidental teaching in the classroom. The author provided feedback to instructors using a four-part feedback-delivery model.

"The components were: (a) praise for correct responses; (b) description of the incorrect responses; (c) description and role-playing of alternative correct responses; and (d) empathetic statement for practice." (Ryan et al., 2008).

Immediately following training and prior to recording Post-training data, one incidental teaching training poster was placed in each classroom. There was an increase in dependent responses in Experiment 2. The findings suggest that brief staff training is an important initial step in improving incidental teaching and student initiations.

The Ryan et al.'s (2008) Experiments 1 and 2 provided evidence for the effectiveness of a brief staff training procedure for incidental teaching which was demonstrated on a smallscale and then a large-scale basis.

\section{Conclusion}

In summary, applied behavior analysis (ABA) is the treatment of choice for students with autism. ABA is the scientific approach to teaching that specifies the importance of individualized programming and data-based decisions that is critical in the education for students with autism. Two effective ABA teaching procedures were discussed in the current chapter. Discrete-trial teaching and incidental teaching have been found to improve the rate of learning by students with autism. Both teaching procedures are designed to target specific goals for the student. Each procedure systematically improves upon learned responses by the student. Staff training research has been conducted in order to teach others how to use discrete-trial and incidental teaching procedures. Effective training procedures 
were reviewed in the current chapter. The Ryan \& Hemmes (2005) method described for training discrete-trial teaching responses was successful in training a high level of accuracy. The two experiments described from Ryan, et al. (2008) provide evidence for the effectiveness of brief staff training procedures implements on a small-scale and on a largescale in a school for students with autism. The author suggests that training on teaching procedures described within the chapter is feasible, practical, and efficient in educational programs for students with autism.

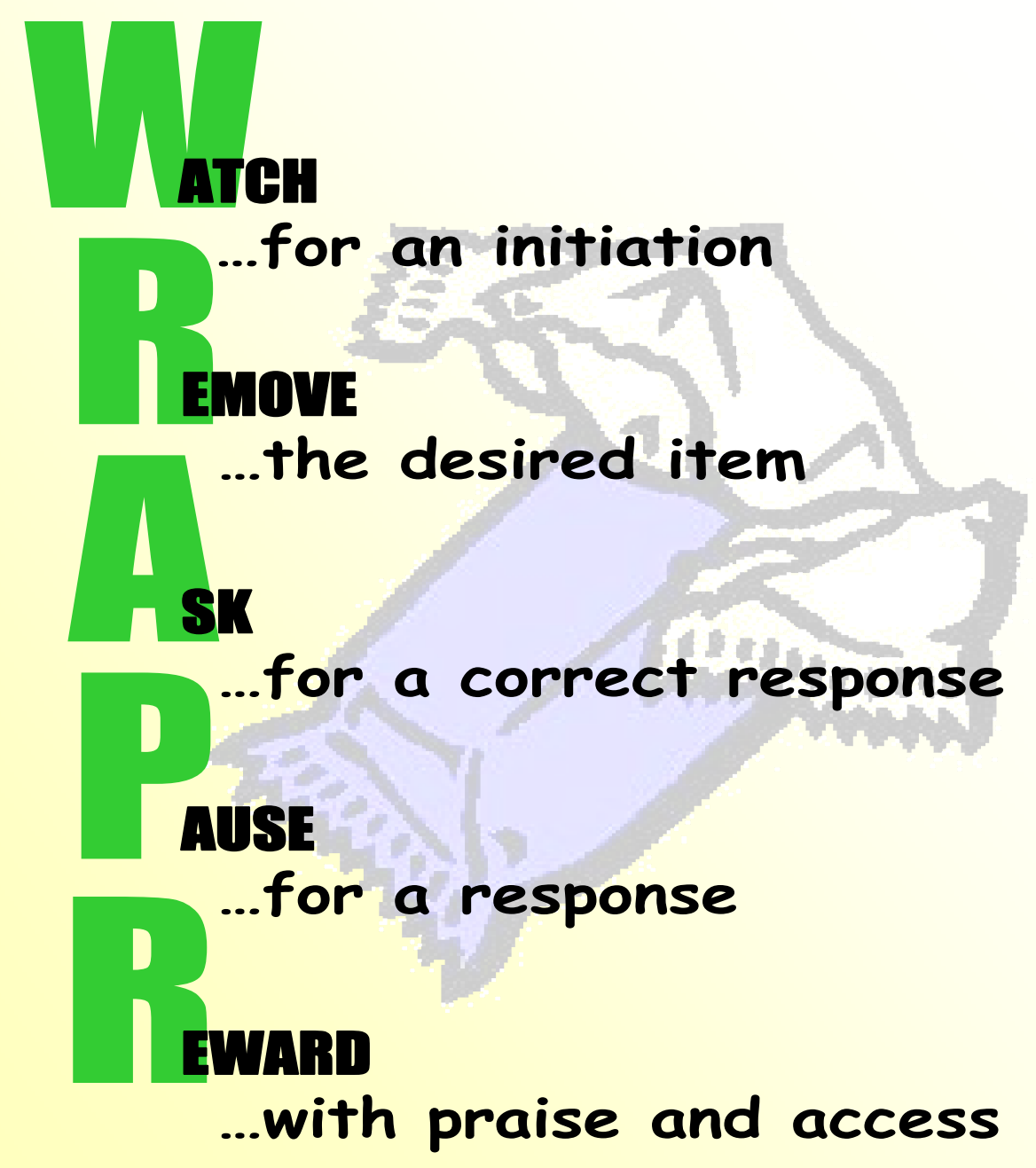

Fig. 6. Diagram of poster and wallet-sized handouts for staff training on incidental teaching responses using in the Ryan, et al. (2008) study. 


\section{Data Sheet for Scoring Incidental Teaching Responses}

Observer name: Session \# Reviewed:

Teacher name: Educational Program:

Session start time and end time (duration):

1. Watch for an initiation: the instructor is available an looking down or away from the student while working.

2. Remove the desired item: after the student makes a verbal or nonverbal initiation for an object, activity, or other event, the instructor removes the item(s) and makes eye contact with the student.

3. Ask for a correct response: the instructor uses an appropriate statement or question to ask the student to say more about the initiation made.

4. Pause for a correct response: the student responds independently or is prompted to respond within $10 \mathrm{~s}$ of the instructor s request.

5. Reward: the instructor presents behavior specific praise about the student s initiation along with access to the object or activity that the student requested.

\begin{tabular}{|l|l|l|l|l|l|l|l|l|l|l|l|l|}
\hline Responses & 1 & 2 & 3 & 4 & 5 & 6 & 7 & 8 & 9 & 10 & Total & $\%$ \\
\hline Watch & & & & & & & & & & & & \\
\hline Remove & & & & & & & & & & & & \\
\hline Ask & & & & & & & & & & & & \\
\hline Pause & & & & & & & & & & & & \\
\hline Reward & & & & & & & & & & & & \\
\hline Total & & & & & & & & & & & & \\
\hline$\%$ & & & & & & & & & & & & \\
\hline
\end{tabular}

Fig. 7. Incidental teaching data sheet used in Ryan et al. (2008) during training. Reprinted with permission of the author. 
Date:

Data Sheet for Scoring Incidental Teaching Responses: Instructor \& Learner Session\#/Tape\#/Duration: Program:

Watch for an initiation: the instructor is available and waits for the student s initiation; the instructor is looking down or away from the student while working. Remove the desired item: after the student makes a verbal or nonverbal initiation for an object, activity, or other event, the instructor removes the item(s) and makes eye contact with the student.

Ask for a correct response: the instructor uses an appropriate statement or question to ask the student to say more about the initiation made.

Pause for a correct response: the student responds independantly or is prompted to respond within $10 \mathrm{~s}$ of the instructor s request.

Reward: the instructor presents behavior specific praise about the students initation along with access to the object or activity that the student requested L.In: Learner Initiation; LR: Learner Response; Pr: Prompted response; Er. Error response; S: Successful episode; U: Unsuccessful episode

\begin{tabular}{|c|c|c|c|c|c|c|c|c|c|c|c|c|c|c|c|c|c|}
\hline & 1 & 2 & 3 & 4 & 5 & 6 & 7 & 8 & 9 & 10 & 11 & 12 & 13 & 14 & 15 & $\begin{array}{c}\text { Total } \\
+\end{array}$ & $\begin{array}{c}\text { Total } \\
-\end{array}$ \\
\hline$w$ & +- & +- & +- & +- & +- & +- & +- & +- & +- & +- & +- & +- & +- & +- & +- & & \\
\hline$\#$ L.In & & & & & & & & & & & & & & & & & \\
\hline $\mathbf{R}$ & +- & +- & +- & +- & +- & +- & +- & +- & +- & +- & +- & +- & +- & +- & +- & & \\
\hline A & +- & +- & +- & +- & +- & +- & +- & +- & +- & +- & +- & +- & +- & +- & +- & & \\
\hline $\mathbf{P}$ & +- & +- & +- & +- & +- & +- & +- & +- & +- & +- & +- & +- & +- & +- & +- & & \\
\hline$L R$ & +- & +- & +- & +- & +- & +- & +- & +- & +- & +- & +- & +- & +- & +- & +- & & \\
\hline Pr & $\begin{array}{l}+- \\
\mathrm{NA}\end{array}$ & $\begin{array}{l}+- \\
\mathrm{NA}\end{array}$ & $\begin{array}{l}+- \\
\mathrm{NA}\end{array}$ & $\begin{array}{l}+- \\
\mathrm{NA}\end{array}$ & $\begin{array}{l}+- \\
\mathrm{NA}\end{array}$ & $\begin{array}{l}+- \\
\mathrm{NA}\end{array}$ & $\begin{array}{l}+- \\
\mathrm{NA}\end{array}$ & $\begin{array}{l}+- \\
\mathrm{NA}\end{array}$ & $\begin{array}{l}+- \\
\mathrm{NA}\end{array}$ & $\begin{array}{l}+- \\
\mathrm{NA}\end{array}$ & $\begin{array}{l}+- \\
\mathrm{NA}\end{array}$ & $\begin{array}{l}+- \\
\mathrm{NA}\end{array}$ & $\begin{array}{l}+- \\
\mathrm{NA}\end{array}$ & $\begin{array}{l}+- \\
\mathrm{NA}\end{array}$ & $\begin{array}{l}+- \\
\mathrm{NA}\end{array}$ & & \\
\hline \#Pr & & & & & & & & & & & & & & & & & \\
\hline$E r$ & $\begin{array}{l}+- \\
\mathrm{NA}\end{array}$ & $\begin{array}{l}+- \\
\mathrm{NA}\end{array}$ & $\begin{array}{l}+- \\
\mathrm{NA}\end{array}$ & $\begin{array}{l}+- \\
\mathrm{NA}\end{array}$ & $\begin{array}{l}+- \\
\text { NA }\end{array}$ & $\begin{array}{l}+- \\
\text { NA }\end{array}$ & $\begin{array}{l}+- \\
\text { NA }\end{array}$ & $\begin{array}{l}+- \\
\mathrm{NA}\end{array}$ & $\begin{array}{l}+- \\
\text { NA }\end{array}$ & $\begin{array}{l}+- \\
\text { NA }\end{array}$ & $\begin{array}{l}+- \\
\text { NA }\end{array}$ & $\begin{array}{l}+- \\
\text { NA }\end{array}$ & $\begin{array}{l}+- \\
\text { NA }\end{array}$ & $\begin{array}{l}+- \\
\mathrm{NA}\end{array}$ & $\begin{array}{l}+- \\
\text { NA }\end{array}$ & & \\
\hline$\#$ Er & & & & & & & & & & & & & & & & & \\
\hline$R$ & +- & +- & +- & +- & +- & +- & +- & +- & +- & +- & +- & +- & +- & +- & +- & & \\
\hline Episode & $\begin{array}{l}\mathrm{S} \\
\mathrm{U}\end{array}$ & $\begin{array}{l}\mathrm{S} \\
\mathrm{U}\end{array}$ & $\begin{array}{l}\mathrm{S} \\
\mathrm{U}\end{array}$ & $\begin{array}{ll} \\
\mathrm{S} \\
\end{array}$ & $\begin{array}{l}\mathrm{S} \\
\mathrm{U}\end{array}$ & $\begin{array}{l}\mathrm{S} \\
\mathrm{U}\end{array}$ & $\begin{array}{l}\mathrm{S} \\
\mathrm{U}\end{array}$ & $\begin{array}{l}\text { S } \\
U\end{array}$ & $\begin{array}{l}\mathrm{S} \\
\mathrm{U}\end{array}$ & $\begin{array}{l}\mathrm{S} \\
\mathrm{U}\end{array}$ & $\begin{array}{l}S \\
U\end{array}$ & $\begin{array}{ll}S \\
U\end{array}$ & $\begin{array}{l}\mathrm{S} \\
\mathrm{U}\end{array}$ & $\begin{array}{l}\mathrm{S} \\
\mathrm{U}\end{array}$ & $\begin{array}{l}\mathrm{S} \\
\mathrm{U} \\
\end{array}$ & & \\
\hline Total S & & & & & & & & & & & & \multicolumn{6}{|c|}{ Total Correct Responses: } \\
\hline Total U & & & & & & & & & & & & \multicolumn{6}{|c|}{ Total Incorrect Responses: } \\
\hline $\begin{array}{l}\text { Type } \\
\text { of Info } \\
\text { Asked }\end{array}$ & \multicolumn{8}{|c|}{$\begin{array}{ll}\text { Request } & \text { Yes/No } \\
\text { Comments } & \text { Number Id. } \\
\text { Object Id. } & \text { Taste Questions }\end{array}$} & \multicolumn{9}{|c|}{$\begin{array}{ll}\text { Conversation__ } & \text { Other_- } \\
\text { Color Id. } & \text { Praise_ } \\
\text { Body Part Id. }\end{array}$} \\
\hline
\end{tabular}

Fig. 8. Incidental teaching datasheet used after training. Reprinted with permission of the author.

\section{Acknowledgment}

The author wishes to acknowledge her former and current colleagues and students from whom she has learned so much. She also expresses her gratitude for her professors from Queens College and the Graduate School and University Center of the City University of New York, CUNY for their inspiration and guidance.

\section{References}

Arco, L. (1991). Effects of outcome performance feedback on maintenance of client and staff behavior in a residential setting. Behavioral Residential Treatment, 6, 231-247.

Baer, D. M., Wolf, M. M., \& Risley, T. R. (1968). Some current dimensions of applied behavior analysis. Journal of Applied Behavior Analysis, 1, 91-97.

Cooper, J. O., Heron, T. E., \& Heward, W. L. (2007). Applied behavior analysis. Upper Saddle River, NJ: Pearson Education, Inc.

Cullen, C. (1988). A review of staff training: The emperor's old clothes. Irish Journal of Psychology, 9, 309-323. 
Delamater, A. M., Conners, C. K., \& Wells, K. C. (1984). A comparison of staff training procedures: Behavioral applications in the child psychiatric inpatient setting. Behavioral Modification, 8, 39-58.

Demchak, M., Kontos, S., \& Neisworth, J. T. (1992). Using a pyramid model to teach behavior management procedures to childcare providers. Topics in Early Childhood Special Education, 12, 458-477.

Fielding, L. T., Errickson, E., \& Bettin, B. (1971). Modification of staff behavior: A brief note. Behavior Therapy, 2, 550-553.

Fleming, R. K., Oliver, J. R., \& Bolton, D. M. (1996). Training supervisors to train staff: A case study in a human service organization. Journal of Organizational Behavior management, 16, 3-25.

Gardner, J. M. (1972). Teaching behavior modification to nonprofessionals. Journal of Applied Behavior Analysis, 5, 517-521.

Gladstone, B. W., \& Spencer, C. J. (1977). The effects of modeling on the contingent praise of mental retardation counselors. Journal of Applied Behavior Analysis, 10, 75-84.

Greene, B. F., Willis, B. S., Levy, R., \& Bailey, J. S. (1978). Measuring client gains from staffimplemented programs. Journal of Applied Behavior Analysis, 11, 395-412.

Harchik, A. E., Sherman, J. A., Hopkins, B. L., \& Strouse, M. C. (1989). Use of behavioral techniques by paraprofessional staff: A review and proposal. Behavioral Residential Treatment, 4, 331-357.

Harris, V. W., Bushell, D., Jr., Sherman, J. A., \& Kane, J. F. (1975). Instructions, feedback, praise, bonus payments, and teacher behavior. Journal of Applied Behavior Analysis, 8,462 .

Hart, B. (1985). Naturalistic language training techniques. In S. Warren, \& A. Rogers-Warren (Eds.), Teaching functional language (pp. 63-88). Baltimore: University Park Press.

Hart, B., \& Risley, T. R. (1974). Using preschool materials to modify the language of disadvantaged children. Journal of Applied Behavior Analysis, 7, 243-256.

Hart, B., \& Risley, T. R. (1975). Incidental teaching of language in the preschool. Journal of Applied Behavior Analysis, 8, 411-420.

Hart, B., \& Risley, T. R. (1980). In vivo language intervention: Unanticipated general effects. Journal of Applied Behavior Analysis, 13, 407-432.

Hart, B., \& Risley, T. R. (1982). How to use incidental teaching for elaborating language. Lawrence, KS: H \& H Enterprises.

Hart, B., \& Risley, T. R. (2000). Meaningful differences in the everyday experience of young American children. Baltimore, MD: Paul H. Brookes.

Hay, L. R., Nelson, R. O., \& Hay, W. M. (1977). The use of teachers as behavior observers. Journal of Applied Behavior Analysis, 10, 345-348.

Johnson, M. D., \& Fawcett, S. B. (1994). Courteous service: Its assessment and modification in a human service organization. Journal of Applied Behavior Analysis, 27, 145-152.

Krumhus, K. M., \& Malott, R. W. (1980). The effects of modeling and immediate and delayed feedback in staff training. Journal of Organizational Behavior Management, 2, 279-293.

Lovaas, O. I. (1987). Behavioral treatment and normal educational and intellectual functioning in young autistic children. Journal of Consulting and Clinical Psychology, $55,3-9$. 
McGee, G. G., Krantz, P. J., \& McClannahan, L. E. (1985). The facilitative effects of incidental teaching on preposition use by autistic children. Journal of Applied Behavior Analysis, 18, 17-31.

McGee, G. G., Krantz, P. J., Mason, D., \& McClannahan, L. E. (1983). A modified incidentalteaching procedure for autistic youth: Acquisition and generalization of receptive object labels. Journal of Applied Behavior Analysis, 16, 329-338.

Matson, J. L. (1990). Handbook of behavior modification with the mentally retarded. New York: Plenum Press.

Neef, N. A., Parrish, J. M., Egel, A. L., \& Sloan, M. E. (1986). Training respite care providers for families with handicapped children: Experimental analysis and validation of an instructional package. Journal of Applied Behavior Analysis, 19, 105-124.

New York State Department of Health (1999a). Clinical practice guideline on autism/pervasive developmental disorders assessment and intervention for young children: Review of recommendations. New York: Author.

New York State Department of Health (1999b). Clinical practice guideline on autism/pervasive developmental disorders assessment and intervention for young children: Quick reference guide. New York: Author.

New York State Department of Health (1999c). Clinical practice guideline on autism/pervasive developmental disorders assessment and intervention for young children: The guideline technical report. New York: Author.

Newman, B., Reeve, K. F., Reeve, S. A., \& Ryan, C. S. (2003). Behaviorspeak. New York: Free Press.

Page, T.J., Iwata, B.A., \& Reid, D.H. (1982). Pyramidal training: A large-scale application with institutional staff. Journal of Applied Behavior Analysis, 15, 335-351.

Parsons, M. B., \& Reid, D. H. (1995). Training residential supervisors to provide feedback for maintaining staff teaching skills with people who have severe disabilities. Journal of Applied Behavior Analysis, 28, 317-322.

Parsons, M. B., Reid, D. H., \& Green, C. W. (1996). Training basic teaching skills to community and institutional support staff for people with severe disabilities: A one-day program. Research in Developmental Disabilities, 17, 467-485.

Parsons, M. B., Schepis, M. M., Reid, D. H., McCarn, J. E., \& Green, C. W. (1987). Expanding the impact of behavioral staff management: A large-scale, long-term application in schools serving severely handicapped students. Journal of Applied Behavior Analysis, 20, 139-150.

Quilitch, H. R. (1975). A comparison of three staff-management procedures. Journal of Applied Behavior Analysis, 8, 59-66.

Reid, D. H., \& Green, C. W. (1980). Staff training. In J. L. Matson (Ed.), Handbook of Behavior Modification with the Mentally Retarded ( $p p$. 71-90). New York: Plenum Press.

Richman, G. S., Riordan, M. R., Reiss, M. L., Pyles, D. A. M., \& Bailey, J. S. (1988). The effects of self-monitoring and supervisor feedback on staff performance in a residential setting. Journal of Applied Behavior Analysis, 21, 401-409.

Ryan, C. S., \& Hemmes, N. S. (2005). Post-training discrete-trial teaching performance by instructors of young children with autism in early intensive behavioral intervention. The Behavior Analyst Today, 6, 1-12.

Ryan, C. S., Hemmes, N. S., Sturmey, P., Jacobs, J. D., \& Grommet E. K. (2008). Effects of a brief staff training procedure on instructors' use of incidental teaching and learners' 
frequency of initiation toward instructors. Research in Autism Spectrum Disorders, 2, $28-45$.

Sarakoff, R. A., \& Sturmey, P. (2004). The effects of behavioral skills training on staff implementation of discrete-trial teaching. Journal of Applied Behavior Analysis, 37, 535-538.

Sepler, H. J., \& Myers, S. L. (1978). The effectiveness of verbal instruction on teaching behavior-modification skills to nonprofessionals. Journal of Applied Behavior Analysis, 11, 198.

Smith, T. (2001). Discrete trial training in the treatment of autism. Focus on Autism \& Other Developmental Disabilities, 16, 86-92.

Sundberg, M. L., \& Partington, J. W. (1998). Teaching language to children with autism or other developmental disabilities. Pleasant Hill, CA: Behavior Analysts, Inc.

Touchette, P. E., \& Howard, J. S. (1984). Errorless learning: Reinforcement contingencies and stimulus control transfer in delayed prompting. Journal of Applied Behavior Analysis, $17,175-188$.

U.S. Department of Health and Human Services. Mental Health: A Report of the Surgeon General - Executive Summary. (1999).

Rockville, MD: U.S. Department of Health and Human Services, Substance Abuse and Mental Health Services Administration, Center for Mental Health Services, National Institutes of Health, National Institute of Mental Health.

Wolf, M. M. (1978). Social validity: The case for subjective measurement, or how applied behavior analysis is finding its heart. Journal of Applied Behavior Analysis, 11, 203214 . 


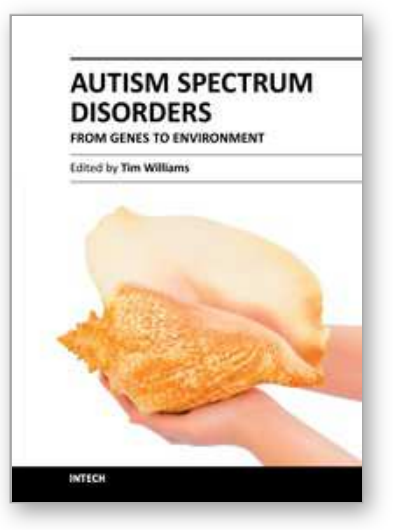

\author{
Autism Spectrum Disorders - From Genes to Environment \\ Edited by Prof. Tim Williams
}

ISBN 978-953-307-558-7

Hard cover, 400 pages

Publisher InTech

Published online 06, September, 2011

Published in print edition September, 2011

Autism spectrum disorders are a major topic for research. The causes are now thought to be largely genetic although the genes involved are only slowly being traced. The effects of ASD are often devastating and families and schools have to adapt to provide the best for people with ASD to attain their potential. This book describes some of the interventions and modifications that can benefit people with ASD.

\title{
How to reference
}

In order to correctly reference this scholarly work, feel free to copy and paste the following:

Carolyn S. Ryan (2011). Applied Behavior Analysis: Teaching Procedures and Staff Training for Children with Autism, Autism Spectrum Disorders - From Genes to Environment, Prof. Tim Williams (Ed.), ISBN: 978-953307-558-7, InTech, Available from: http://www.intechopen.com/books/autism-spectrum-disorders-from-genesto-environment/applied-behavior-analysis-teaching-procedures-and-staff-training-for-children-with-autism

\section{INTECH}

open science | open minds

\author{
InTech Europe \\ University Campus STeP Ri \\ Slavka Krautzeka 83/A \\ 51000 Rijeka, Croatia \\ Phone: +385 (51) 770447 \\ Fax: +385 (51) 686166 \\ www.intechopen.com
}

\author{
InTech China \\ Unit 405, Office Block, Hotel Equatorial Shanghai \\ No.65, Yan An Road (West), Shanghai, 200040, China \\ 中国上海市延安西路65号上海国际贵都大饭店办公楼 405 单元 \\ Phone: +86-21-62489820 \\ Fax: +86-21-62489821
}


(C) 2011 The Author(s). Licensee IntechOpen. This chapter is distributed under the terms of the Creative Commons Attribution-NonCommercialShareAlike-3.0 License, which permits use, distribution and reproduction for non-commercial purposes, provided the original is properly cited and derivative works building on this content are distributed under the same license. 